\title{
Bevacizumab in the Treatment of Metastatic Breast Cancer
}

\author{
Florian Schuetz Christof Sohn Andreas Schneeweiss \\ Breast Unit, University of Heidelberg, Germany
}

Key Words

Angiogenesis - VEGF - Targeted therapy .

Metastatic breast cancer

\section{Summary}

Vascular endothelial growth factor (VEGF) is the major positive regulator of its receptor (VEGFR2) which mediates angiogenesis physiologically as well as in malignant diseases. Many tumors secrete high levels of VEGF leading to a high number of newly built peritumoral blood vessels, which has been identified as an independent prognostic indicator for tumor recurrence and survival in breast cancer. Therefore, inhibiting angiogenesis may be an effective antitumor treatment in breast cancer as well as in other malignant diseases. Bevacizumab is a potent humanized monoclonal antibody to VEGF, which has shown regression of solid tumors in clinical and preclinical trials alone or in combination with cytotoxic treatment. Phase I/II trials showed significant antitumor effects of bevacizumab against several solid tumors including breast cancer. Toxicities were moderate including hypertension, bleeding and proteinuria. A first phase III trial in pretreated metastatic breast cancer $(\mathrm{MBC})$ patients who had received prior chemotherapy for metastatic disease showed better response rates but no benefit from the addition of bevacizumab to capecitabine with regard to progression-free and overall survival. However, in another phase III trial in patients with $\mathrm{MBC}$ without prior systemic treatment for metastases, bevacizumab improved progression-free survival in combination with weekly paclitaxel in comparison to paclitaxel alone. Bevacizumab in combination with paclitaxel seems to be a highly effective first-line treatment for MBC patients. Further trials will have to show its effects in other indications.

\section{Schlüsselwörter}

Angiogenese · VEGF · Zielgerichtet Therapie . Metastasiertes Mammakarzinom

\section{Zusammenfassung}

Der vaskuläre Wachstumsfaktor (VEGF) ist der stärkste positive Regulator des vaskulären Wachstumsfaktor Rezeptors 2 (VEGFR2), der die Angiogenese physiologisch und auch bei malignen Erkrankungen reguliert. Zahlreiche Tumoren sezernieren hohe Konzentrationen des VEGF, was zu einer erhöhten Dichte neu gebildeter peritumoraler Blutgefäße führt, die der Tumor zum Wachstum benötigt. Eine erhöhte Angiogeneserate wurde als unabhängiger Faktor bezüglich der Rezidivrate und des Gesamtüberlebens bei Brustkrebs identifiziert. Aus diesem Grund wurde vermutet, dass eine Hemmung der Angiogenese eine effektive antitumoröse Therapie sowohl des Mammakarzinoms als auch anderer Tumorentitäten darstellen könnte. Bevacizumab ist ein hoffnungsvoller humaner monoclonaler Antikörper gegen VEGF, der in klinischen und präklinischen Studien solider Tumoren allein oder auch in Kombination mit anderen Wirkstoffen ein signifikantes Ansprechen gezeigt hat. In Phase-I/II-Studien konnten bei Patientinnen mit Brust- und anderen Krebserkrankungen Remissionen beobachtet werden, wobei eine moderate Rate an Nebenwirkungen vor allem durch Hypertonie, Blutungen und Proteinurie bedingt war. In einer ersten Phase-III-Studie bei teilweise stark vorbehandelten metastasierten Mammakarzinompatientinnen konnte zwar eine verbesserte "Response Rate» in Kombination mit Capecitabin gegen Capecitabin allein gezeigt werden, doch schlug sich diese nicht in dem krankheitsfreien oder Gesamtüberleben nieder. In einer anderen Phase-III-Studie bei zytostatisch nicht vorbehandelten metastasierten Mammakarzinompatientinnen konnte jedoch die Kombination aus Paclitaxel und Bevacizumab gegen die Paclitaxel-Monotherapie eine signifikante Verlängerung des krankheitsfreien Überlebens bewirken. Die Kombination mit Paclitaxel scheint also eine effektive Kombinationstherapie des metastasierten Mammakarzinoms zu sein. Andere Indikationen werden derzeit in Studien untersucht.

\begin{tabular}{ll}
\hline KARGER & @ 2007 S. Karger GmbH, Freiburg \\
$\begin{array}{l}\text { Fax +49 7614 5207 14 } \\
\begin{array}{l}\text { E-mail Information@Karger.de } \\
\text { www.karger.com }\end{array}\end{array}$ & $\begin{array}{l}\text { Accessible online at: } \\
\text { www.karger.com/brc }\end{array}$ \\
&
\end{tabular}

Prof. Dr. med. Andreas Schneeweiß

Universitätsklinikum Heidelberg

Universitäts-Frauenklinik

Voßstr. 7-9, 69115 Heidelberg, Germany

Tel. +49 6221 56-35552, Fax -7920

E-mail andreas_schneeweiss@med.uni-heidelberg.de 


\section{Introduction}

Although researchers and clinicians have reached impressive improvements in the prognosis for cancer patients during the last decades, survival rates have now begun to plateau. Therefore, alternative ways of treating malignancy have to be explored. One way seems to be the destruction of newly built peri- and intratumoral blood vessels that a tumor needs to grow. The concept of targeting the developing vascular supply of a new tumor (antiangiogenic therapy) was introduced by Folkman in 1971 [1]. Angiogenesis is a process that describes the physiological as well as pathological generation of new blood vessels which was first explored in embryonic cells during rapid endothelial cellular proliferation. In contrast to the embryonic and childhood phase of a human being, there seems to be decreased angiogenic activity in normal adult tissues after development is completed [2]. While angiogenesis is a physiological process that naturally occurs and is controlled by 'on' and 'off' switches, building new blood vessels in malignant tumors seems to be an uncontrolled phenomenon. Malignant cells can alter endogenous angiogenic pathways and retard antiangiogenic factors, thus providing an imbalance in blood vessel formation. Extensive laboratory data suggest that angiogenesis plays an essential role in breast cancer development, invasion, and metastasis [3]. Microscopic metastases are growth-restricted $(<2 \mathrm{~mm})$ due to the need of oxygen and nutrients. They remain dormant until they undergo an 'angiogenic switch', presumably a result of further mutation. Hypoxia is a key signal for the induction of angiogenesis next to several other factors (IL-8, growth factors, oncogenes). Increased angiogenesis has been identified as an independent prognostic indicator for tumor recurrence and survival, with increased levels of angiogenesis and elevated tumor microvessel density linked with poor prognosis in multiple malignancies, including breast cancer [4].

Involved in physiological as well as pathological mechanisms is a special group of peptides -the most important ones called vascular endothelial growth factors (VEGF) - and transmembranous receptors (vascular endothelial growth factor receptor (VEGFR) (fig. 1). VEGFs are glycoproteins mediating numerous functions of endothelial cells including proliferation, migration, invasion, survival, and permeability. Of all the members of the large VEGF family (VEGF-A, -B, -C, -D, -E), VEGF-A is the most active [5]. Upon VEGF-As binding VEGFR, autophosphorylation (p-VEGFR) on tyrosine residues located in the cytoplasmic part takes place activating several signaling pathways that ultimately lead to angiogenesis and endothelial cell proliferation. VEGFR2, also known as KDR or Flk-1, is the most active receptor in angiogensis [6]. It contains seven immunoglobulin-like loops extracellularly, and split tyrosine kinase domains in the intracellular domain.

Expression of VEGF - but not VEGFR - has been demonstrated inside multiple tumors including breast cancer [7], colon cancer [8], gastrointestinal stromal tumors [9], renal cancer [10], and lung cancer [11]. In contrast, the surrounding stromal vasculature of these tumors has demonstrated expression of VEGFR but not of VEGF [12], leading to the hypothesis that the development of new blood vessels is under the order of the tumor's VEGF. Thus, increasing levels of VEGF expression have been correlated with increasing microvessel density and poor prognosis.

Several studies have found an inverse correlation between VEGF expression and overall survival in both node-positive and node-negative breast cancer $[13,14]$. Increased VEGF expression has also been associated with impaired response to tamoxifen or chemotherapy in patients with advanced breast cancer [15].Transfection of tumor cells with angiogenic stimulatory peptides increases tumor growth, invasiveness, and metastasis. Conversely, transfection of tumor cells with inhibitors of angiogenesis decreases growth and metastasis [5].

There are different ways to inhibit tumor angiogenesis. Antibodies against VEGF, antibodies against active extracellular parts of VEGFR or molecules against the VEGFR's intracellular domain (tyrosine kinase inhibitor) or intracellular signaling cascade are possible strategies that are under investigation in clinical as well as preclinical trials. This review focuses on the antibody bevacizumab (Avastin ${ }^{\mathrm{TM}}$, Roche Pharma AG, Grenzach-Whylen, Germany) that targets VEGF.

\section{Preclinical Trials}

\section{Murine Antibody Against VEGF (A4.6.1)}

Kim et al. [16] were the first to demonstrate inhibition of tumor growth in nude mice, using a murine monoclonal antibody called A4.6.1 which was directed against isomers of VEGF. It showed in vitro and in vivo excellent antitumor activity in different tumors with marked areas of necrosis, reduced tumor diameter, and frequency of peritumoral blood vessels (fig. 2). The murine anti-VEGF antibody was subsequently evaluated in combination with cisplatin in nude mice, with additive effects seen in comparison to either agent used alone. Interestingly, the number and size of metastases decreased under treatment whereas tumors started re-growing following antibody withdrawal [17].

\section{Human Antibody against VEGF (Bevacizumab)}

Bevacizumab is a humanized monoclonal antibody to VEGF that recognizes all isoforms of VEGF-A and prevents it from attaching to the VEGFR. In in vivo studies with different solid tumors, bevacizumab showed similar results to A4.6.1 as monotherapy but even higher anti-tumor effects in combination with chemo- and radiation therapy $[18,19]$. 
Fig. 1. Interactions of VEGF and VEGF receptor and possible ways to inhibit this pathway.

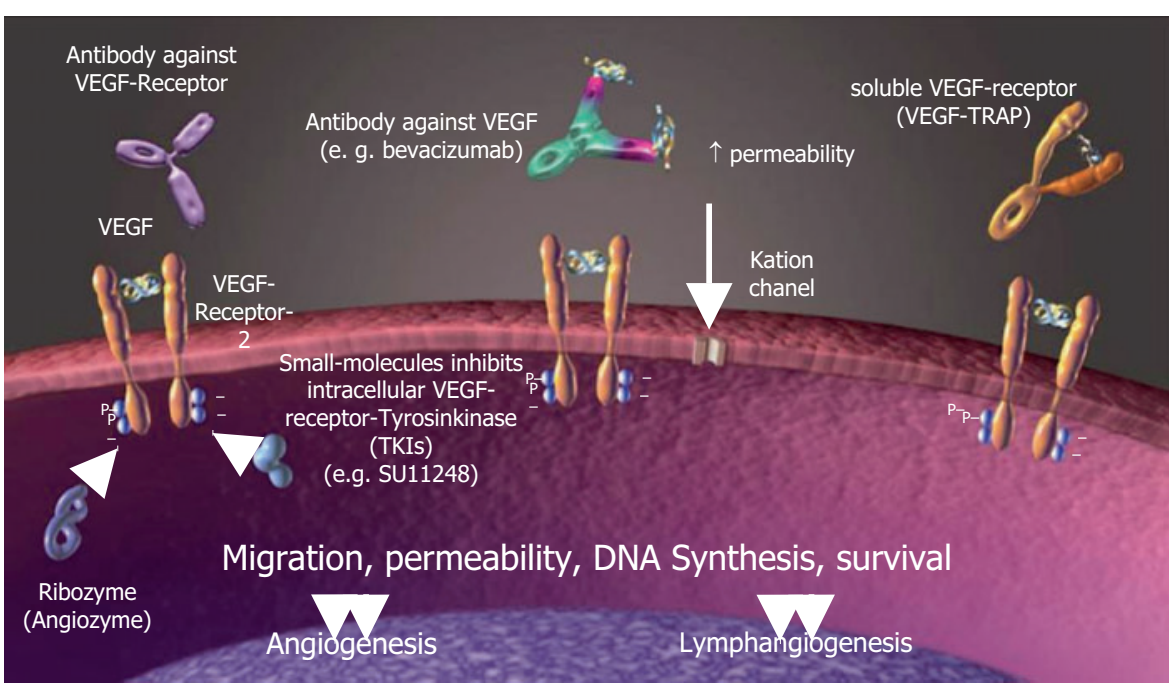

\section{Clinical Trials}

In clinical trials, bevacizumab was tested as monotherapy as well as in combination with cytotoxic agents in a variety of tumors. Especially capecitabine, paclitaxel, and trastuzumab seem to have synergistic effects in the treatment of solid tumors [20]. In colorectal [21], renal [22], and breast cancer, bevacizumab showed significant activity in clinical trials. It is US Food and Drug Administration (FDA)-approved for first-line treatment of metastatic colorectal cancer.

As with the development of trastuzumab, however, we have to keep in mind that testing antiangiogenic agents in clinical trial is different from testing cytotoxic agents in the same setting. First, these agents have to be delivered in a fashion that explores the biologically optimal rather than the maximum tolerated dose due to the mechanism of action and the time of treatment. Second, the therapeutic goal is the long-term control of the disease rather than the direct killing of tumor cells which necessitates chronic therapy as opposed to an intermittent one as has been observed in several trials examining antiangiogenic activity of chemotherapeutic agents [23]. Therefore, measuring response rates and progression-free survival by using RECIST criteria alone may not reflect the efficacy of these agents.

\section{Phase I Trials}

Feasibility and toxicities of bevacizumab treatment in humans were evaluated in early human clinical trials. In a phase I trial by Gordon et al. [24], bevacizumab was administered as monotherapy to 25 patients with advanced malignancies including breast cancer. Escalating doses of bevacizumab from 0.1 to $10 \mathrm{mg} / \mathrm{kg}$ were given intravenously with repeated dosing without dose-limiting toxicity. Corresponding Cmax values ranged from 2.8 to $284 \mu \mathrm{g} / \mathrm{ml}$. Patients subsequently received bevacizumab on days $1,28,35$ and 42 , with final follow-up on day 72. Pharmacokinetic studies indicated linear kinetics with a half-life of 21 days, and doses of bevacizumab equal to or greater than $0.3 \mathrm{mg} / \mathrm{kg}$ completely suppressed free serum VEGF levels. Toxicities were felt to be acceptable, and further investigation of the agent warranted, although bleeding complications would need further monitoring. 1 patient demonstrated a minor response, and 11 patients showed stable disease.

A combination of weekly bevacizumab with 3 different chemotherapy regimens (single-agent doxorubicin, carboplatin with paclitaxel, or 5-fluorouracil with leucovorin) in patients with advanced cancer including breast cancer was evaluated in a phase $\mathrm{Ib}$ trial simultaneously published [24]. 12 patients were enrolled, with 3 experiencing disease regression. 4 patients developed diarrhea, leucopenia, and thrombocytopenia. No hemorrhagic or thrombotic complications were noted in this study. No pharmacological interactions were noted between bevacizumab and the different chemotherapeutic regimens, and half-life was confirmed to be 13 days [25]. In an extension treatment study by Langmuir et al. [26] for patients enrolled in phase I or II trials with bevacizumab (administered every 2-3 weeks), 52 patients received further treatment with bevacizumab. 28 patients were treated with bevacizumab for longer than 1 year. Of these 28 patients, 5 experienced deep venous thrombosis, 3 experienced grade 2 or 3 hypertension, and 1 patient experienced grade 1 proteinuria. 2 patients with colorectal cancer experienced gastrointestinal hemorrhage grade 2 and grade 4 , respectively.

Furthermore, a phase I/II dose escalation trial of bevacizumab as a single agent in patients with metastatic breast cancer who have progressed on at least 1 standard-of-care agent has been reported [27]. A total of 75 patients were treated: 18 patients received $3 \mathrm{mg} / \mathrm{kg}$, 41 patients received $10 \mathrm{mg} / \mathrm{kg}$, and 16 patients received $20 \mathrm{mg} / \mathrm{kg}$ every 2 weeks; 12 (16\%) patients received all 13 doses. Objective response rate was confirmed in $6.7 \%$ of patients. $4(5.3 \%)$ patients discontinued the study due to an adverse drug event (encephalopathy, nephrotic syn- 
Fig. 2. Early and long-lasting effects of bevacizumab on tumor vessels.

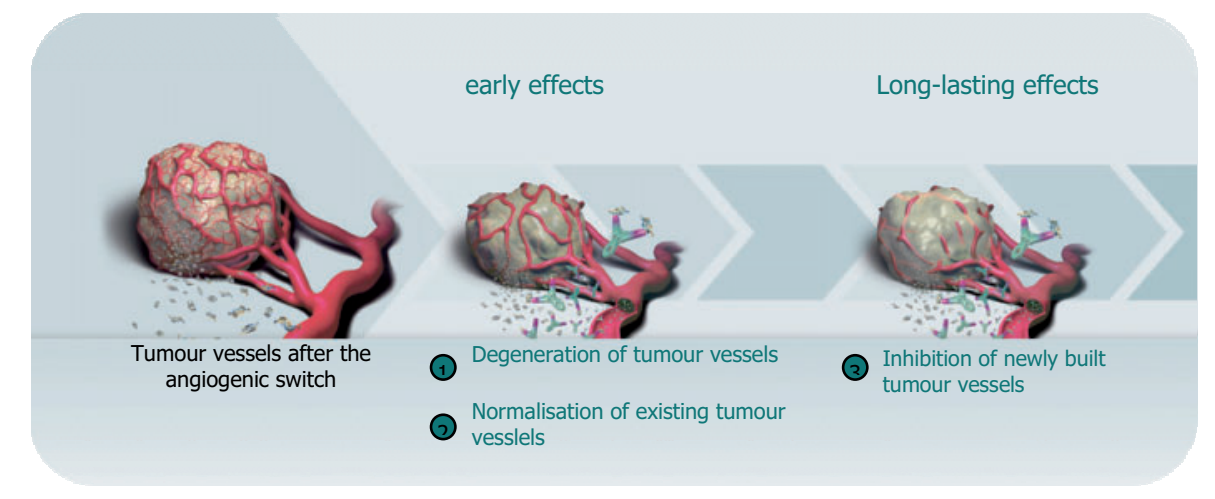

drome and proteinuria). Reported grade 3 and 4 toxicities were consistent with other single-agent bevacizumab trials, and included asthenia (9\%), headache (7\%), hypertension (19\%), myalgia (4\%) and arthralgia (4\%).

\section{Phase II Trials in Metastatic Breast Cancer}

Sledge et al. [28] performed a randomized phase II trial with single-agent bevacizumab in 35 patients with pretreated metastatic breast cancer who had progressed on at least 1 anthracycline- or taxane-based regimen in 2 different doses. Patients were treated every 2 weeks until progression of disease or to a maximum of 13 infusions. Fatal events were not reported. However, 2 episodes of hypertension were documented, one of which was coupled with nephrotic syndrome. 1 patient in the low-dose $(3 \mathrm{mg} / \mathrm{kg})$ arm demonstrated partial response, and 1 patient in the high dose $(10 \mathrm{mg} / \mathrm{kg})$ arm demonstrated complete response of disease.

A phase I/II dose escalation study of bevacizumab in escalating doses for 75 patients with previously treated metastatic breast cancer published by Cobleigh et al. [27] noted an overall response rate of $6.7 \%$, with a median duration of response of 5.5 months. In this study, $5.4 \%$ of patients enrolled discontinued therapy secondary to adverse events, with 1 patient experiencing hypertensive encephalopathy with nephrotic syndrome, and 1 patient each experiencing proteinuria, nephrotic syndrome, and headache with nausea and vomiting. 4 patients experienced headache with nausea and vomiting at the dose of $20 \mathrm{mg} / \mathrm{kg}$, rendering this a dose-limiting toxicity. In total, $20 \%$ of enrolled patients experienced serious adverse events in this study, which were fairly evenly distributed between the different dose levels of bevacizumab. Toxicities included 5 patients with hypertension (including the patient with hypertensive encephalopathy), 2 patients with central line-associated subclavian and axillary vein thrombosis, 4 patients with headache with nausea and vomiting, and 2 patients experiencing congestive heart failure (both having previously been treated with doxorubicin). No episodes of significant bleeding were noted, although $25.3 \%$ of enrolled patients experienced grade 1 bleeding events (mostly mild epistaxis not felt to be clinically significant). The dose of bevacizumab at $10 \mathrm{mg} / \mathrm{kg}$ every 2 weeks was again recommended as the ideal dose for further evaluation in clinical trials. Further phase II trials in metastatic breast cancer have combined bevacizumab with a variety of other agents including vinorelbine [29] and docetaxel [30] and showed positive results as well.

\section{Phase III Studies in Breast Cancer}

A phase III trial testing bevacizumab has been reported by Miller et al. [31] (table 1). This two-arm study randomly assigned 462 patients with anthracycline and taxane refractory, metastatic breast cancer to receive capecitabine $(2,500$ $\mathrm{mg} / \mathrm{m}^{2} /$ day for 14 out of 21 days) with or without bevacizumab (15 mg/kg every 3 weeks). Considering the primary end point of this study (time to progression), there was neither evidence of improvement in the bevacizumab arm (4.86 vs. 4.17 months; hazard ratio $(\mathrm{HR})=0.98, \mathrm{p}=$ not significant (n.s.)) nor a benefit in overall survival (15.1 vs. 14.5 months, $p=n . s$.). The combination, however, significantly increased the objective response rates (9.1 vs. $19.8 \%$; $\mathrm{p}=0.001)$. Hypertension requiring treatment ( 17.9 vs. $0.5 \%)$, proteinuria (22.3 vs. $7.4 \%)$, and thromboembolic events $(7.4$ vs. $5.6 \%)$ were more frequent in patients receiving bevacizumab, although there were no reports of grade 4 hypertension in the combination arm. Quality of life assessment (FACT-B) showed no differences between both groups. Although attempts to correlate VEGF-RNA overexpression (by in situ hybridization) and response in this study were unsuccessful, the sample size was too small for a definitive conclusion.

In another phase III study done by the Eastern Cooperative Oncology Group (ECOG 2100 study), patients with locally advanced or metastatic breast cancer received paclitaxel $90 \mathrm{mg} / \mathrm{m}^{2}$ weekly for 3 of 4 weeks with or without bevacizumab $10 \mathrm{mg} / \mathrm{kg}$ every 2 weeks as first-line therapy [32]. All patients were pretreated with anthracyclines in the adjuvant setting. Primary endpoint was progression-free survival; response was assessed by RECIST criteria every 3 cycles. While 722 patients were enrolled (680 patients were eligible), hypertension that has to be treated occurred in $16.0 \%$ of patients on the bevacizumab arm, versus $2.0 \%$ patients receiving chemotherapy alone $(\mathrm{p}<0.0001)$. Grade 3 or 4 proteinuria was noted in 
Table 1. Comparison of bevacizumab toxicities in phase III studies of different cancers

\begin{tabular}{|c|c|c|c|c|c|c|c|c|}
\hline Study [Ref.] & $\begin{array}{l}\text { Cancer } \\
\text { type }\end{array}$ & $\begin{array}{l}\text { Patients, } \\
\mathrm{n}\end{array}$ & Combination & $\begin{array}{l}\text { Dosis be- } \\
\text { vacizumab } \\
(\mathrm{mg} / \mathrm{kg})\end{array}$ & $\begin{array}{l}\text { Hypertension } \\
\text { grade } 3 \text { or } \\
\text { greater, } \%\end{array}$ & $\begin{array}{l}\text { Proteinuria } \\
\text { grade III } \\
\text { or greater, \% }\end{array}$ & $\begin{array}{l}\text { Thromboembolic } \\
\text { event grade III } \\
\text { or greater, \% }\end{array}$ & $\begin{array}{l}\text { Hemorrhage } \\
\text { grade III or } \\
\text { greater, \% }\end{array}$ \\
\hline Miller et al. 2006 [32] & breast & 722 & $\begin{array}{l}\mathrm{Bev}+\mathrm{Pac} \\
\text { vs. } \mathrm{Pac}\end{array}$ & 10 & $\begin{array}{l}16.0 \text { vs. } 2.0 \\
(\mathrm{p}<0.0001)\end{array}$ & $\begin{array}{l}2.0 \text { vs. } 0 \\
(\mathrm{p}=0.002)\end{array}$ & $\begin{array}{l}2.0 \text { vs. } 4.0 \\
(p=\text { n.s. })\end{array}$ & $\begin{array}{l}3.0 \text { vs. } 0.0 \\
(p=0.02)\end{array}$ \\
\hline Miller et al. 2005 [31] & breast & 462 & $\begin{array}{l}\text { Bev + Cap } \\
\text { vs. Cap }\end{array}$ & 15 & 17.9 vs. 0.5 & 0.9 vs. 0 & 5.6 vs. 3.7 & 0.4 vs. 0.5 \\
\hline Sandler et al. 2006 [45] & lung & 878 & $\begin{array}{l}\mathrm{Bev}+\mathrm{Pac} / \\
\text { Carb vs. Pac/ } \\
\text { Carb }\end{array}$ & 15 & $\begin{array}{l}6.0 \text { vs. } 0.7 \\
(p<0.001)\end{array}$ & & & $\begin{array}{l}4.5 \text { vs. } 0.7 \\
(p<0.001)\end{array}$ \\
\hline Hurwitz et al. 2004 [21] & colon & 813 & $\begin{array}{l}\text { Bev + IFL } \\
\text { vs. IFL }\end{array}$ & 5 & 11.0 vs. 2.3 & $\begin{array}{l}0.8 \text { vs. } 0.8 \\
\text { ( } \mathrm{p}=\text { n.s. })\end{array}$ & $\begin{array}{r}19.4 \text { vs. } 16.2 \\
\text { (all grades) }\end{array}$ & $\begin{array}{l}3.1 \text { vs. } 2.5 \\
\text { (p }=\text { n.s.) }\end{array}$ \\
\hline
\end{tabular}

$\mathrm{Bev}=$ Bevacizumab $; \mathrm{Cap}=$ capecitabine; $\mathrm{Pac}=$ paclitaxel $\mathrm{Carb}=$ carboplatin, $\mathrm{IFL}=$ irinotecan, fluorouracil and leucovorin; $\mathrm{n} . \mathrm{s} .=$ not significant.

$2.0 \%$ of patients receiving bevacizumab $(0 \%$ with chemotherapy alone, $\mathrm{p}=0.0004)$. In patients treated with bevacizumab, asymptomatic proteinuria occurred more often (21 patients developing proteinuria vs. 2 patients in the control group). Grade 3 and 4 bleeding was seen more often in the bevacizumab arm ( 3.0 vs. $0 \%, p=0.02)$. Grade 3 and 4 neuropathy was more commonly seen in patients treated with bevacizumab (20.2 vs. $14.2 \%$ with chemotherapy alone, $p=0.01)$. No differences were observed in thromboembolic or hemorrhagic events in either treatment arm (1.5\% in both groups). The combination of bevacizumab plus paclitaxel did not compromise quality of life, assessed by FACT-B and FACT-G score. 2 patients discontinued therapy secondary to initiation of anticoagulation. The recently published data reported a median progression-free survival for the combination arm of 11.40 months as compared to 6.11 months in the paclitaxel alone arm $(\mathrm{HR}=0.51, \mathrm{p}<0.0001)$. Overall response rate was 29.9 vs. $13.8 \%(\mathrm{p}<0.0001)$, respectively. In an early analysis presented at San Antonio Breast Cancer Symposium 2005 [32], a significant improvement in overall survival was noted with the addition of bevacizumab to chemotherapy ( $\mathrm{HR}=0.674$, $\mathrm{p}=0.01$ ), but in the latest analysis with 275 events only a trend remains toward better overall survival without significance (28.4 vs. 25.2 months; $\mathrm{HR}=0.84, \mathrm{p}=0.12$ ).

These promising data of bevacizumab as first-line therapy in metastatic breast cancer have to be confirmed in another phase III trial that is currently taking place in Europe (Avastin and docetaxel as first line therapy in metastatic breast cancer (AVADO trial).

\section{Neoadjuvant Setting of Primary Breast Cancer}

Effects of bevacizumab in primary tumors of the breast have been evaluated in 2 recently published neoadjuvant trials. In the first study, primary breast cancer patients with unresectable tumors were treated with docetaxel with or without bevacizumab. Metastatic as well as non-metastatic patients were enrolled. Patients whose disease responded underwent definitive surgery followed by 4 cycles of doxorubicin/cyclophosphamide and tamoxifen (if hormone receptor-positive). There were 5 complete clinical responses and 24 partial responses, and the therapy was generally well tolerated [33].

Wedam et al. [34] recently reported results of a National Cancer Institute neoadjuvant study evaluating bevacizumab in women with inflammatory breast cancer. Patients received bevacizumab alone for the first cycle $(15 \mathrm{mg} / \mathrm{kg})$ followed by 6 cycles of bevacizumab with doxorubicin $\left(50 \mathrm{mg} / \mathrm{m}^{2}\right)$ and docetaxel $\left(75 \mathrm{mg} / \mathrm{m}^{2}\right)$ every 3 weeks. After locoregional therapy patients received 8 cycles of bevacizumab alone, and endocrine therapy when indicated. A significant decrease of phosphorylated VEGFR2 in tumor cells and a increase in tumor apoptosis were observed. However, there were no significant changes in microvessel density or VEGF expression. There was also evidence of a decrease in vascular permeability on dynamic contrast-enhanced magnetic resonance imaging after the first cycle of bevacizumab monotherapy. After completion of chemotherapy, 8 of 13 patients experienced a confirmed partial response.

\section{Combination of Bevacizumab with Trastuzumab}

A combination of bevacizumab and HER2 receptor blocking treatment appears very reasonable due to findings in preclinical and clinical studies that HER2 seem to play a central role in the regulation of VEGF $[35,36]$. Several studies have demonstrated that the blockade of epidermal growth factor receptor (EGFR) resulted in an antiangiogenic effect [37]. In a preclinical study, exposure to trastuzumab significantly decreased VEGF in HER2-overexpressing cells [38]. In vivo experiments have shown reduction in xenograft volume using a combination of trastuzumab and bevacizumab compared with single-agent control. Furthermore, in a cohort of 611 patients with primary breast cancer and a median follow-up of $>50$ months, there was a significant positive association between 
HER2 and VEGF expression [39]. On the other hand, it was shown that VEGF is also able to regulate EGFR pathways. Data have suggested that an increased production of VEGF represents one mechanism by which tumor cells escape antiEGFR monoclonal antibody therapy [40].

A phase I trial has evaluated the tolerability of the combination of bevacizumab with trastuzumab. It was determined that co-administration of these 2 humanized monoclonal antibodies did not alter the pharmacokinetics of either agent. Clinical responses were observed in 5 of 9 patients, including 1 patient with prior disease progression on chemotherapy plus trastuzumab [41]. A phase III trial is underway (bevacizumab, trastuzumab and docetaxel as first-line therapy in HER2-positive metastatic breast cancer (AVEREL trial)). One trial has tested the combination of bevacizumab and erlotinib an EGFR tyrosine kinase inhibitor in metastatic breast cancer. This combination demonstrated activity and also found that changes in circulating endothelial cells and circulating tumor cells may correlate with response to this combination [42].

\section{Future Trials}

In combination with paclitaxel, bevacizumab enhanced efficacy in first-line therapy in metastatic breast cancer patients while toxicities were manageable [32]. However, in pretreated metastatic breast cancer, a combination of capecitabine and bevacizumab showed a lack of benefit in comparison to capecitabine alone, which may represent the poor prognosis due to tumor heterogeneity as well as the choice of chemotherapy. In metastatic breast cancer patients, the combination partner of bevacizumab seems to play a central role as well as the line of therapy. Combinations with several agents, like do- cetaxel [30], vinorelbin [29], carboplatin, and nab-paclitaxel [43], were positively tested. An ongoing trial led by the North Central Cancer Treatment Group is testing the combination of docetaxel, capecitabine, and bevacizumab as first-line chemotherapy in patients with metastatic breast cancer. Preliminary results of a combination therapy with bevacizumab and everolimus, a mTOR-inhibitor, were shown [44].

However, future trials do not have to concentrate on the combination partners only. The time point of treatment is also of major interest. It was suggested that angiogenesis occurs in the very early stages of tumor development (micrometastases), which gives a strong rationale for an adjuvant antiangiogenic treatment. The Eastern Cooperative Oncology Group is planning an adjuvant feasibility trial evaluating bevacizumab in combination with dose-dense doxorubicin and cyclophosphamide followed by paclitaxel in women with node-positive primary breast cancer.

\section{Conclusion}

Bevacizumab has shown in many cancers its efficacy as combination partner with several cytostatic therapies. Its toxicities are manageable. Therefore, bevacizumab will play an increasing role as an investigational and therapeutic agent in metastatic breast cancer. Future trials will show whether bevacizumab has a positive influence on the prognosis of primary breast cancer patients in the adjuvant or neoadjuvant setting. However, there is a need for a better understanding of the mechanisms of action (especially in combination with other targeted therapies) as well as of the toxicities of bevacizumab.

\section{References}

1 Folkman J: Tumor angiogenesis: therapeutic implications. N Engl J Med 1971;285:1182-1186.

2 Millauer B, Wizigmann-Voos S, Schnurch H, et al.: High affinity VEGF binding and developmental expression suggest Flk-1 as a major regulator of vasculogenesis and angiogenesis. Cell 1993;72: 835-846.

3 Schneider BP, Miller KD: Angiogenesis of breast cancer. J Clin Oncol;23:1782-1790.

4 Toi M, Hoshina S, Takayanagi T, Tominaga I: Association of vascular first endothelial growth factor expression with tumor angiogenesis and with early first relapse in primary breast cancer. Jpn J Cancer Res 1994:85:1045-1049.

5 Miller K, Siedge GW: Dimming the blood tide: angiogenesis. antiangiogenic therapy end breast cancer; in Nabholtz JM (ed): Breast Cancer Management Application of Clinical end Translational Evidence to Patient Care (2nd ed). Philadelphia, PA, Lippincott Williams \& Wilkins, 2003, pp. 287-308.

6 Ferrara N, Davis-Smyth T: The biology of vascular endothelial growth factor. Endocr Rev 1997;18: 4-25.

$\checkmark 7$ Brown LF, Berse B, Jackman RW, et al.: Expression of vascular permeability factor (Vascular endothelial growth factor) and its receptors in breast cancer. Hum Pathol 1995;26:86-91.
8 Takahashi Y, Kitadai Y, F, Bucana CD, Cleary Kr, Ellis LM: Expression of vascular endothelial growth factor and its receptor, KDR, correlates with vascularity, metastasis, and proliferation of human colon cancer. Cancer Res 1995;55: 3964-3968.

9 Takahashi R, Tanaka S, KitadaI Y, et al.: Expression of vascular endothelial growth factor and anglogenesis in gastrointestinal stromal tumor of the stomach. Oncology 2003;64:266-274.

10 Mellado B, Gascon P: Molecular biology of renal cell carcinoma. Clin Transl Oncol 2006;8:706-710.

11 Maeda K, Chung Y-S, Ogawa Y, et al.: Prognostic value of vascular endotheliaI growth factor expression in gastric carcinoma. Cancer 1996;77:858-863.

12 Brown LF, Berse B, Jackman RW, et al.: Expression of vascular permeability factor (vascular endothelial growth factor) and its receptors in adenocarcinomas of the gastrointestinal tract. Cancer Res 1993;53:4727-4735.

13 Gasparini G, Toi M, Gion M, et al.: Prognostic significance of vascular endothelial growth factor protein in node-negative breast carcinoma. J Natl Cancer Inst 1997;89:139-147.
14 Gasparini G, Toi M, Miceli R, et al.: Clinical relevant of vascular endothelial growth factor and thymidine phosphorylase in patients with nodepositive breast cancer treated with either adjuvant chemotherapy or hormone therapy. Cancer J Sci Am 1999;5:101-111.

15 Foekens JA, Peters HA, Grebenchtchikov N, et al High tumor levels of vascular endothelial growth factor predict pool response to systemic therapy in advanced breast cancer. Cancer Res 2001;61: 5407-5414.

16 Kim KJ, Li B, Winer J, et aI.: Inhibition of vascular endothelial growth factor-induced angiogenesis suppresses tumour growth in vivo. Nature 1993;362: 841-844.

17 Zhu Z, Bohlen P, Witte L: Clinical development of angiogenesis inhibitors to vascular endothelial growth factors and its receptors as cancer therapeutics. Curr Cancer Drug Targets 2002;2:135-156.

18 Presta LG, Chen H, O'Connor SJ, et al.: Humanization of an anti-vascular endothelial growth factor monoclonal antibody for the therapy for solid tumors and other disorders. Cancer Res 1997;57: 4593-4599.

19 Jain RK: Normalizing tumor vasculature with antiangiogenic therapy: a new paradigm for combination therapy. Nat Med 2001;7:987-989. 
20 Shen BQ, Stainton S, Li D, Pelletier N, Zioncheck TF: Combination of avastin and capecitabine synergistically inhibits colorectal tumor growth in a COLO205 tumor xenograft model. Proc Am Assoc Cancer Res 2004;45:508(abstr 2203).

21 Hurwitz H, Fehrenbacher L, Novotny W, et al.: Be vacizumab plus irinotecan, fluorouracil and leucovorin for metastatic colorectal cancer. N Engl J Med 2004:350:2335-2342.

22 Yang IC, Hawgrowth L, Sherry RM, et al.: A randomized trial of bevacizumab an antivascular endothelial growth factor antibody for metastatic renal cancer. N Engl J Med 2003;349:427-434.

23 Sweeney C, Siedge G: Chemotherapy agents as antiangiogenic therapy. Cancer Conference Highlights 1999;3:2-4.

-24 Gordon MS, Margolin K, Talpaz M, et al.: Phase I safety and pharmacokinetic study of recombinant human anti-vascular endothelial growth factor in patients with advanced cancer. J Clin Oncol 2001; 19:843-850.

25 Margolin K, Gordon MS, Holmgren H, et al.: Phase $\mathrm{Ib}$ trial of intravenous recombinant humanized monoclonal antibody to vascular endothelial growth factor in combination with chemotherapy in patients with advanced cancer: pharmacologic and long-term safety data. J Clin Oncol 2001;19: 851-856.

26 Langmuir VK, Cobleigh MA, Herbst RS, et al.: Successfullong-term therapy with bevacizumab (Avastin) in solid tumors. Proc Am Soc Clin Oncol 2002;21:abstr 32

27 Cobleigh MA, Langmuir VK, Sledge GW, et al.: A phase I/II dose-escalation trial of bevacizumab in previously treated metastatic breast cancer. Semin Oncol 2003;30:117-124.

28 Sledge G, Miller K, Novotny W, et al.: A phase II trial of single-agent Rhumab VEGF (recombinant humanized monoclonal antibody to vascular endotheliaI cell growth factor) in patients with relapsed metastatic breast cancer. Proc Am Soc Clin Oncol 2000;19:abstr 5C.
29 Burstein H, Parker L, Savoie J, et al.: Phase II trial of the anti-VEGF antibody bevacizumab in combination with vinorelbine for refractory advanced breast cancer. Breast Cancer Res Treat 2002;76: S115(abstr 446).

30 Ramaswamy B, Rhoades C, Kendra K, et al.: Phase II trial of bevacizumab in combination with weekly docetaxel in metastatic breast cancer patients. Clin Cancer Res 2006;12:3124-3129.

31 Miller K, Chap LI, Holmes FA, et al.: Randomized phase III trial of capecitabine compared with bevacizumab plus capecitabine in patients with previously treated metastatic breast cancer. J Clin Oncol 2005;23:792-799.

32 Miller KD, Wang M, Gralow J, et al.: A randomized phase III trial of paclitaxel versus paclitaxel plus bevacizumab as first-line therapy for locally recurrent or metastatic breast cancer: a trial coordinated by the Eastern Cooperative Oncology Group (E2100). Europ J Canc 2006; 46:suppl 4.

33 Overmoyer B, Silverman P, Leeming R, et al.: Phase II trial of neoadjuvant docetaxel with or without bevacizumab in patients with locally advanced breast cancer. Breast Cancer Res Treat 2004;88:S106(abstr 2088).

34 Wedam S, Low J, Yang X, et al.: Antioangiogenic and antitumor effects of bevacizumab in patients with inflammatory and locally advanced breast cancer. J Clin Oncol 2006;24:769-777.

35 Koukourakis MI, Giatromanolaki A, O'Byrne KJ, et al.: bcl-2 and c-erbB-2 proteins are involved in the regulation 01 VEGF and 01 thymidine phosphorylase angiogenic activity in non-small-cell lung cancer. Clin Exp Metastasis 1999;17:545-554.

36 Clarke K, Smith K, Gullick WJ, et al.: Mutant epidermal growth lactat receptor enhances induction of vascular endothelial growth lactat by hypoxia and insulin-like growth lactor-1 via a PI3 kinase dependent pathway. Br J Cancer 2001;84:1322-1329.

37 Bruns CJ, Solorzano CC, Harbison MT, et al.: Blockade of the epidermal growth lactate receptor signaling by a novel tyrosine kinase inhibitor leads to apoptosis of endothelial cells and therapy of human pancreatic carcinoma. Cancer Res 2000;60: 2926-2935.
38 Epstein M, Ayala R, Tchekmedyian N, et al.: HER2-overexpressing human breast cancer xenografts exhibit increased angiogenic potential mediated by vascular endothelial growth lactate (VEGF). Breast Cancer Res Treat 2002;76:S143 (abstr 570).

39 Konecny GE, Meng YG, Untch M, et al.: Association between HER-2/neu and vascular endothelial growth lactor expression predicts clinical outcome in primary breast cancer pa- tients. Clin Cancer Res 2004;10:1706-1716.

40 Viloria-Petit A, Crombet T, Jothy S, et al.: Acquired resistance to the antitumor ellect 01 epidermal growth factor receptor-blocking antibodies in vivo: a role for altered tumor angio-genesis. Cancer Res 2001;61:5090-5101.

41 Pegram M, Yeon C, Ku N, et al.: Phase I combined biological therapy 01 breast cancer using two humanized monoclonal antibodies directed against HER2 proto-oncogene and vascular endothelia growth lactor (VEGF). Breast Cancer Res Treat 2004;88:S124(abstr 3039).

42 Rugo H, Dickler M, Statt J, et al.: Circulating endothelial tell (CEC) and tumor cell (CTC) analysis in patients receiving bevacizumab and erlotinib for metastatic breast cancer (MBC). Breast Cancer Res Treat 2004;88:5142(abstr 3088).

43 Bernstein JA, Schubbert T, Kong K, Mehta RS Weekly carboplatin and nab-paclitaxel plus trastuzumab, or plus or minus bevacizumab: clinical response in patients with breast cancer. Proc Am Soc Clin Oncol 2006;24:abstr 10699.

44 Zafar Y, Bendell J, Lager D, et al.: Preliminary results of a phase I study of bevacizumab in combination with everolimus in patients with advanced solid tumors. Proc Am Soc Clin Oncol 2006;24: abstr 3097.

45 Sandler A, Gray R, Perry MG, et al: Placlitaxelcarboplatin alone or with bevacizumab for nonsmall-cell lung cancer. N Engl J Med 2006;355: 2542-2550. Erratum in N Engl J Med 2007:356:318. 